\title{
UNHA ACHEGA Ó ESTUDO DO PROCESO DE CODIFICACIÓN OR- TOGRÁFICA E GRAMATICAL DA LINGUA GALEGA (1980-2000).
}

\author{
Paulo Sánchez Vidal
}

IES Lagoa de Antela (Xinzo de Limia)

Gustaríame agradecer, antes de comezar este relatorio, aos organizadores deste encontro, en concreto a todos e cada un dos membros do Instituto da Lingua Galega e do Consello da Cultura Galega, a súa xenerosa invitación a participar neste foro de reflexión sobre a interesante e, ás veces, controvertida cuestión da variación e a prescrición.

A codificación ortográfica e gramatical do noso idioma, como sabe toda persoa que teña mostrado un mínimo de interese por esta cuestión, foi, é, e probablemente será nun futuro, un dos temas máis comprometidos, enleados e espiñentos de cantos se teñen tratado ata este momento no ámbito da lingüística galega. Ante a complexidade interna e amplitude bibliográfica que comporta o proceso de codificación ortográfica e gramatical da nosa lingua desde 1980 ata o ano 2000 parece pertinente adoptar un ton xeral de mesura que prescinda, en todo momento, de afirmacións categóricas que puidesen dar a impresión de que pretendemos ir máis aló dunha visión panorámica e provisional de todo este período. E isto debe ser así, segundo o meu parecer, porque nunca debemos esquecer que, por moito que teñamos investigado sobre esta cuestión, por moito que nos apoiemos na forza dos datos contrastados e por moito que creamos que sabemos tocante á codificación ortográfica da nosa lingua, sempre haberá feitos concretos do noso obxecto de estudo que, ou ben puidesen ter escapado á nosa tensión investigadora, ou ben, posibilidade en absoluto desbotable e mesmo desexable, puidesen ser susceptibles de interpretacións discordantes coa nosa.

En definitiva, cómpre recoñecer que esta é unha visión persoal e propia do acontecido ao longo de todo este período que como moito aspira a ser unha outra contribución, como reza o título deste relatorio, para un coñecemento máis profundo e miúdo do camiñar evolutivo do estándar da nosa lingua. 


\section{AS CORRENTES CODIFICATORIAS EN CONFLITO E OS SEUS FUNDAMENTOS TEÓRICOS}

Tocante ao debate sobre o proceso de codificación ortográfica da lingua galega no período cronolóxico que se estende, aproximadamente, desde o ano 1980 ata a actualidade, a maioría dos especialistas na materia viñan diferenciando dúas grandes liñas codificatorias que, polo común, recibían as denominacións de orientación autonomista e orientación reintegracionista respectivamente.

Agora ben, malia que a visión dos feitos que subxace a esta parella terminolóxica goce da aceptación máis ou menos xeneralizada de círculos eruditos así como de ámbitos non estritamente académicos preocupados por esta cuestión, cremos que non estaría fóra de lugar ensaiar (ao abeiro da información colleitada como base de traballo para a redacción dunha memoria de licenciatura presentada na Facultade de Filoloxía da Universidade de Santiago de Compostela no ano 2000 baixo o título de Contribución ó estudo do proceso de codificación ortográfica e gramatical do galego: orientacións, conflicto e fases do debate normativo ${ }^{1}$ ) estoutra proposta de organización interna para o debate codificatorio da nosa lingua. Nestoutra hipótese de traballo, sempre susceptible, claro está, de ulteriores precisións e revisións, ás correntes codificatorias xa coñecidas por todos en maior ou menor medida, engadimos neste traballo unha terceira perspectiva para a codificación ortográfica da nosa lingua que, en consonancia cos seus propios defensores, tomamos a determinación de designar coa etiqueta de orientación lusofonófila.

En consecuencia, segundo o punto de vista que aquí defenderemos e daremos a coñecer, no periplo cronolóxico que abre o ano 1980 poderiamos diferenciar tres correntes no debate sobre a codificación ortográfica da nosa lingua: a orientación autonomista, a orientación reintegracionista e por último a orientación lusofonófila.

Con todo, é obvio que esta proposta de organización interna da polémica codificatoria en tres correntes, e non en dúas como viña sendo ata agora habitual, só tería xustificación en tanto en canto como investigadores: $1^{\circ}$ ) soubesemos recoñecer en cada unha das correntes en conflito, cando menos, un principio individualizador e $2^{\circ}$ ) fosemos quen de explicitar ese principio así como as consecuencias que del se extraen.

Así pois, este traballo debe, se desexamos dotar de pleno sentido ás nosas reflexións analíticas, primeiro, camiñar pola senda da análise e identificación dos fundamentos que alicerzan cada unha das correntes para o debate

1 Esta memoria de licenciatura, mellorada e ampliada segundo as directrices marcadas polo seu tribunal cualificador, será publicada proximamente. Aí poderá encontrar a persoa interesada unha relación bibliográfica máis completa. 
ortográfico e gramatical do noso idioma, e segundo, unha vez concluído este labor, penetrar nas diferentes propostas normativas que destes principios se derivan.

A orientación autonomista presenta como principio nucleador e vertebrador de si mesma o constructo teórico que os investigadores veñen designando nos últimos anos como Tese ou Teoría da Individualización Sociolingüistica. Esta teoría, que naceu como edificio teórico máis ou menos consciente e fechado ao longo da década dos anos oitenta do século pasado, considera que na Iberorromania occidental conviven na actualidade dúas Linguas por Elaboración (Ausbau) modernas, a lingua galega e a lingua portuguesa, que se foron conformando paseniño como tales Linguas por Elaboración nos períodos cronolóxicos que van desde o século XIX ata a actualidade e desde o século XVI ao XIX respectivamente.

A defensa do galego como Lingua Elaborada moderna independente da Lingua Elaborada portuguesa aséntase, en esencia, sobre dous criterios de índole extralingüística, para sermos exactos de carácter sociolingüístico: $1^{\circ}$ ) a consciencia plurisecular da comunidade lingüística galega de posuírmos un idioma propio diferente da lingua portuguesa e da lingua castelá e $2^{\circ}$ ) os esforzos desde o Rexurdimento por elaborar un estándar autónomo e propio para o nosa lingua así como na reivindicación explícita e efectiva do seu uso.

A Tese ou Teoría da Individualización sociolingüistica reivindica, en consecuencia, unha variedade estándar autónoma e propia para a lingua galega non subordinada directa ou indirectamente á variedade estándar da lingua portuguesa en atención a: $1^{\circ}$ ) fidelidade á tradición espontánea de cultivo autónomo da nosa lingua desde o século XIX, manifestación en última instancia, como xa vimos, dunha consciencia idiomática autónoma fronte ao castelán e ao portugués e $2^{\circ}$ ) un principio de tipo práctico que ansía a singularización da comunidade lingüística galega fronte ás comunidades castelanófona e lusófona ademais da rearticulación da nosa comunidade lingüística mediante a incorporación ou reincorporación ao ámbito lingüístico galegófono dos individuos, en número crecente, castelanófonos.

Non obstante, os teóricos da Tese ou Teoría da Individualización Sociolingüistica son asemade conscientes, cando menos aqueles que se declaran seguidores da chamada lingüistica relativística así como do modelo relativistico que dela emana (p. ex. Žarko Muljačić 1990, 1991a, 1991b, 1991c, 1995, 1999), de que a lingua galega manifesta no momento actual unha incuestionable subordinación funcional con respecto á variedade estándar do español dado que os nosos falantes (ben na dimensión de simples falantes, ben na vertente de oíntes ou lectores) executan nolentes volentes unha parte (en ocasións considerable e substancial) dos seus actos lingüísticos nun castelán 
máis ou menos correcto (ou se se prefire máis ou menos incorrecto). Precisamente, se atendésemos en exclusiva a esta limitación funcional o idioma galego podería ser caracterizado como unha $L$ (ingua) B(aixa) verbo do castelán estándar²; mais, se focalizásemos a nosa atención, de novo de forma illada, no proceso de planificación da estrutura experimentado pola nosa lingua desde o século XIX con vistas á conformación dunha variedade estándar autónoma e propia quen de supraordinar ás nosas variedades lingüísticas vernáculas, o idioma galego podería ser definido, pola contra, como unha L(ingua) A(lta), esta vez fronte ao galego popular. Daquela acontece, segundo o parecer dos teóricos que defenden a lingüística relativística, que o idioma galego é hoxe en día, ao mesmo tempo, L(ingua) A(lta) e L(ingua) $B$ (aixa), e, polo tanto, como por outra banda tamén lle acontece, por citar só algún dos casos máis coñecidos no contexto do estado español, ao catalán e ao éuscaro, constituiría en realidade o que, desde unha perspectiva sociolingüística, deuse en chamar L(ingua) M(edia).

Con todo, non estaría de máis lembrar que o estatuto de L(ingua) M(edia) non é de carácter estático nin inmutable visto que, como a lingüística relativista permite contemplar, pode variar en dirección ascendente ou descendente no decorrer temporal e conforme ás circunstancias sociais, políticas e económicas que circunden ao idioma galego. Así, se a lingua galega consegue rematar de modo satisfactorio o proceso de conformación dunha variedade estándar e liberarse da súa subordinación funcional á lingua castelá, ascendería ao nivel de L(ingua) A(lta), mais, polo contrario, e na peor das situacións, se a variedade estándar do idioma galego perdese toda capacidade de supraordinación das variedades lingüísticas vernáculas do galego popular, descendería inexorablemente á condición de L(ingua) B(aixa). Esta dobre evolución de índole prospectiva é a que outorga, ao entender da corrente autonomista, a súa auténtica relevancia ao debate sobre a codificación ortográfica da lingua galega dado que, segundo escollamos unha ou outra opción ortográfica, contribuiremos en positivo ou en negativo á ansiada liña ascendente do idioma galego.

En relación a este último punto, a orientación autonomista entende que unha contribución positiva á dirección ascendente da lingua galega pasa, por necesidade (xunto a outros factores), pola elaboración, defensa e reivindicación dunha variedade estándar autónoma e propia para a lingua galega. Con todo, se ben o consenso foi unánime tocante a este principio, non sucedeu o mesmo, consciente ou inconscientemente, coa súa posta en práctica, pois, unha vez que houbo que descender do "ceo dos sabios" ao "inferno

2 Na terminoloxía de José Joaquín Montes Giraldo (1986) a lingua galega sería un dialecto heteroxéneo por subordinación. 
dos humanos", a substanciación efectiva deste principio materializouse non nunha soa proposta normativa, como cabería esperar, senón en varios códigos normativos que pretenderon desenvolver na praxe, todos eles, os fundamentos da orientación autonomista.

En consecuencia, ante a multiplicidade de modelos normativos que buscaron levar a efecto os principios da corrente autonomista, debemos, se queremos aprofundar en capacidade analítica, proceder con suma cautela, posto que, como parecen demostrar as discrepancias entre os estudosos á hora de confeccionar a nómina de modelos normativos de cada orientación, corremos o risco de que as árbores non nos deixen ver o bosque; ou, noutras palabras, corremos o perigo de que as contadas diverxencias que se advirten entre os diferentes modelos normativos da orientación autonomista verbo de puntos moi concretos nos impidan cobrar plena consciencia da común concepción lingüística que durmiña baixo todos eles.

Aínda que como diciamos no parágrafo anterior non existe total acordo entre os investigadores verbo dos códigos normativos que conforman a orientación autonomista, non hai, porén, disensións na convicción de que as Normas ortográficas e morfolóxicas do idioma galego do ano 1982 (en adiante NOMIG 82) son a proposta normativa máis elaborada, completa e representativa do principio que se ten denominado autoxestión lingüistica.

O principio de autoxestión lingüistica, que malia estar sempre presente na corrente autonomista tornouse máis evidente a partir de 1971 -data de creación do Instituto da Lingua Galega (ILG) - implicou de contino un traballo consciente, rigoroso e constante de aprofundamento na realidade lingüística conformada polas variedades lingüísticas vernáculas galegas. A maior abondamento, a posta en efecto deste principio de autonormación conduciu a un método de traballo no cal nunha primeira etapa se procedeu ao estudo rigoroso das estruturas básicas do galego popular no ámbito fonolóxico, morfosintáctico e léxico, logo, a seguir, abriuse un período de atención ao galego escrito para rematar, ao final, coa busca da coherencia interna non só coa propia lingua senón tamén co resto de linguas románicas.

Este principio de autoxestión lingüistica, que permitiu elaborar primeiro modelos normativos non definitivos (estou a pensar por exemplo nas Bases prá unificación das normas lingüísticas do galego de 1977), dotou, á súa vez, aos seus grandes valedores, sobre todo ao ILG, dun coñecemento científico da realidade lingüística do momento abondo profundo como para que fose factible, coas garantías necesarias, dar o grande salto cara a un modelo normativo que aspirase a superar definitivamente o estadio de código provisional. Precisamente con esa angueira naceron as NOMIG 82. As NOMIG 82 foron elaboradas por unha Comisión mixta integrada por membros do Instituto da Lingua Galega da Real Academia Galega, aprobadas en sesión con- 
xunta (ILG/RAG) o 3 de xullo e finalmente publicadas o 17 de novembro de 1982

Fóra do caso das NOMIG 82, ao redor do cal, insistimos, parece non haber dúbida entre os especialistas sobre a súa adscrición á orientación autonomista, encontrámonos con todo un conxunto bastante amplo de códigos normativos que, segundo o investigador en concreto, e en función do punto de vista que este adopte, incluíronse, ou non, na corrente autonomista.

En semellante situación, seguindo unha orde, en primeiro lugar, cronolóxica e, en segundo termo, alfabética, atopámonos coa seguinte nómina de códigos normativos:

$\left(1^{\circ}\right)$ Orientacións para a escrita do noso idioma (1979) da Asociación Socio-Pedagóxica Galega (en adiante Normas da AS-PG 79). As Normas da AS-PG 79 distribuíronse en edición ciclostilada entre os docentes congregados nas III Xornadas do Ensino celebradas en Ourense durante os días 29, 30 e 31 de agosto na entón chamada Universidade Laboral. Uns meses máis tarde aparece unha segunda versión deste texto (Orientacións para a escrita do noso idioma, 1980; a partir de aquí Normas da AS-PG 80), que foran, en síntese, á súa vez, unha reedición aumentada das Normas da AS-PG 79. As normas da AS-PG 80 déronse ao público baixo a forma de dúas edicións minimamente diferenciadas entre si. A segunda edición, ao cargo de Edicións Xistral, realízase en Barallobre (A Coruña) e imprímese en Adral. A terceira edición, tamén a cargo de Edicións Xistral e agora con ilustracións interiores, lévase a cabo en Mariñamansa (Ourense) en Gráficas Rodi. Aínda temos constancia dunha cuarta edición das Normas da AS-PG 79 co título Orientaçóns para a escrita do noso idioma da Asociaçóm Socio-Pedagógica Galega que foron editadas en 1982 (en adiante Normas da AS-PG 82) pero descoñecemos por qué causa, se por erro ou por outro motivo, figuran con data de 1980. Estas últimas, das que falaremos máis polo miúdo ao longo deste estudo, xunto coas outras dúas inmediatamente anteriores, isto é, as tres edicións aparecidas a partir de 1980, curiosamente teñen todas elas o mesmo ISBN (84-85271-20-3) e idéntico DL (C. 451-1980).

$\left(2^{\circ}\right)$ Normas ortográficas do idioma galego (1980) elaboradas pola Comisión de Lingüística da Xunta de Galicia presidida polo profesor Ricardo Carballo Calero (en adiante Normas da Comisión-Xunta 80) e publicadas no número 10 do Boletín Oficial da Xunta de Galicia do mes de xuño de 1980. Seis meses máis tarde, na segunda quincena do mes de decembro dese mesmo ano, a Subcomisión de Programación de Textos da Xunta de Galicia presenta no número quince do Boletín Oficial da Xunta de Galicia unha segunda versión das Normas Ortográficas do idioma galego (desde este momento Normas da Subcomisión-Xunta 80) máis 
achegadas, nesta ocasión, ás Bases prá unificación das normas lingüísticas do galego de 1977.

Tocante ás Normas da AS-PG (AS-PG 79, 80), sería moi interesante, ao noso entender, cara á comprensión cabal da evolución futura do debate sobre a codificación ortográfica da nosa lingua, que tivésemos presente, no momento de situar calquera destes dous modelos normativos nunha ou noutra corrente codificatoria, que a grande maioría dos especialistas, sobre todo a partir da década dos anos 90 do século pasado e mesmo desde posturas diametralmente opostas á autonomista, considera que a aceptación e uso efectivo do sistema ortográfico da lingua castelá debería ser a fronteira metodolóxica primeira e esencial á hora de delimitar os dominios reais non só da orientación autonomista senón tamén, en correlato negativo, da orientación reintegracionista.

En reforzo desta opción metodolóxica, parécenos, tamén, interesante lembrar que unha parte considerable dos estudosos que traballaron sobre as Normas da AS-PG (AS-PG 79, 80) coinciden na percepción de que existe nelas unha implícita consideración do galego como lingua de seu, aspecto que debería primar sobre puntos concretos de achegamento real e incuestionable ao portugués estándar.

Esta aproximación ao código ortográfico do portugués estándar non é, non obstante, unha característica exclusiva da codificación normativa da AS-PG, visto que as Normas da Comisión-Xunta 80, por unha banda, ofertan solucións gráficas dobres (como opción para o presente e sen ningún tipo de restrición), unha delas, sen dúbida, dentro da órbita do espazo gráfico do portugués estándar (p. ex. o uso dos grafemas g e $j$ para o fonema palatal fricativo xordo) e, por outra banda, deixan unha porta aberta á posibilidade global dunha ortografía máis "solidaria" coas opcións gráficas do estándar luso (nesta ocasión, ben a título experimental en círculos eruditos, ben como opción futurible). Desde esta realidade, sería perfectamente aceptable que o investigador, de focalizar o seu centro de interese sobre estes aspectos concretos, excluíse este modelo normativo da orientación autonomista. Así e todo, de acordo cos criterios de delimitación das diferentes correntes codificatorias que bosquexabamos nos parágrafos anteriores, vémonos na obriga de poñer de relevo que: $1^{\circ}$ ) este código normativo acepta de modo explícito e utiliza, na súa praxe ortográfica, destacadas marcas específicas da orientación autonomista (p. ex. o uso do grafema $x$ para o fonema palatal africado xordo) e $2^{\circ}$ ) non recolle na redacción do propio texto auténticos "grafemas símbolo" das correntes codificatorias non autonomistas (p. ex. os dígrafos $n h$ e $l h$ para os fonemas palatal nasal sonoro e palatal lateral sonoro respectivamente). Daquela, cremos que sería máis operativo desde un punto de 
vista metodolóxico, con vistas a reelaborar sobre criterios máis ou menos fixos a nómina de códigos ortográficos que integra cada corrente codificatoria, incluír as Normas da Comisión-Xunta 80 na orientación autonomista.

Á vista do anterior resulta sinxelo advertir que, na práctica, as Normas da AS-PG (AS-PG 79, 80) e as Normas da Comisión-Xunta 80 (dobre posibilidade moito máis xustificada para estas últimas) quedarían fóra ou dentro da orientación autonomista segundo os criterios aos cales dese primacía o investigador. Non pensamos, pola contra, que se puidese facer o mesmo coas Normas da Subcomisión-Xunta 80, na medida en que, quitadas diverxencias moi puntuais (p. ex. tocante ao plural das palabras rematadas en -il átono), estas son, de feito, case unha repetición das Bases prá unificación das normas lingüisticas do galego (1977) e que, por conseguinte, deberían conformar o grupo de códigos normativos de corte autonomista.

Para fechar a nosa análise verbo das propostas normativas que poderían integrar a orientación autonomista, procedemos agora a facer referencia sucinta a outros dous textos que, segundo a nosa opinión, serían tamén parte da orientación autonomista. Estámonos a referir, en concreto, a: $\left.1^{\circ}\right)$ Nova gramática para a aprendizaxe da língua de Costa et al. (desde agora Normas da APLL), na cal, conforme á información que se tira do propio texto, se seguen os criterios normativos da Asemblea da Asociación de Profesores de Língua e Literatura (APLL) e $2^{\circ}$ ) Guia elemental para a escrita do galego. Normativa dos minimos (s. d. [1998]) da Confederación Intersindical GalegaNormalización Lingüística (en adiante Normas da CIG). En solución de continuidade cos criterios de deslinde entre as diferentes correntes normativas que aquí viñemos defendendo, malia que o primeiro dos códigos normativos se autodefina como "normativa de mínimos" e o segundo como "normativa reintegracionista de mínimos", pensamos que a presenza e aceptación nestes dous textos do código ortográfico do castelán sería argumento de suficiente peso e entidade como para situalos dentro da orientación autonomista.

Así pois, o cadro-resumo dos modelos normativos que integran a corrente autonomista tería o seguinte aspecto:

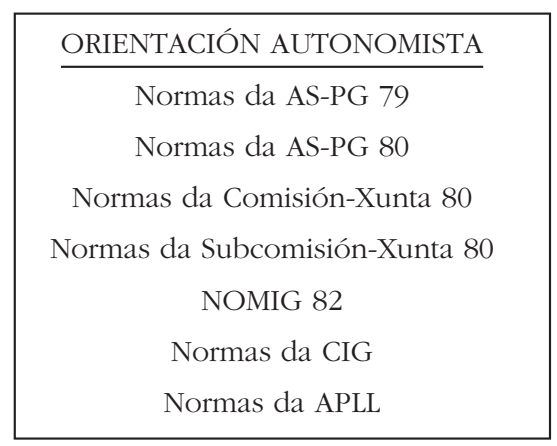


Pasaremos agora, sen máis dilacións, ao estudo da orientación reintegracionista que se asenta, en esencia, segundo a investigadora Sabine Taschenberger (1990:137) no principio que esta estudosa denomina Tese ou Teoría da Reintegración. A Tese ou Teoría da Reintegración, segundo esta mesma especialista (Taschenberger 1990: 137), tería a súa orixe inicial no artigo de Manuel Rodrigues Lapa "A recuperação literária do galego" (Lapa 1973). O carácter iniciático que este artigo tería para a Tese ou Teoría da Reintegración, cando menos para as súas manifestacións máis modernas, goza tamén da aceptación doutros lingüistas como Xesús Ferro Ruibal (1984:208), Johannes Kabatek (1992: 68-69) ou Herrero Valeiro (1993: 186).

A Tese ou Teoría da Reintegración implica para Kabatek (1992: 65) un proxecto consciente de integración ou achegamento ao campo lingüístico portugués e para Taschenberger (1990: 137) comporta unha aproximación ao portugués literario. Definicións deste xorne da corrente reintegracionista aparecen ademais en Benigno Fernández Salgado e Henrique Monteagudo Romero (1995) que entenden que o reintegracionismo carrexa unha vontade de aproximación "máis ou menos rápida do (proto-)estándar galego ó portugués" (Fernández e Monteagudo 1995: 148) ou mesmo en Antón Santamarina, que destaca o feito de que a perspectiva reintegracionista defende un proceso de converxencia co portugués (Santamarina 1995: 74).

O primeiro que chama a atención cando un se achega a este tipo de definicións, tanto da Tese ou Teoría da Reintegración como da orientación reintegracionista no seu conxunto, é o elevado nivel de indeterminación teórica no cal se moven todas elas. Con todo, ao noso entender, o problema non está tanto nas definicións en si mesmas (ou nunha suposta incapacidade dos seus autores para acadar un maior grao de concreción) como no propio concepto de reintegración.

Acontece que a Tese ou Teoría da Reintegración constitúe un edificio especulativo significado polo seu elevado nivel de inconcreción teórica, de modo que baixo a etiqueta de orientación reintegracionista ou reintegracionismo acolléronse diferentes solucións prácticas tan arredadas entre si que mesmo poden ir desde unha mínima aproximación ao portugués estándar en cuestións ortográficas e morfolóxicas (como acontece por exemplo nas Normas da AS-PG 80) á utilización do Acordo Ortográfico de Rio (1986) e o Acordo Ortográfico de Lisboa (1990).

Neste sentido un dos teóricos da órbita da corrente reintegracionista máis prolífico dos últimos anos, Herrero Valeiro (Herrero 1991/1994: 202), recoñece que a etiqueta corrente reintegracionista serve para designar liñas teóricas e prácticas para a codificación ortográfica da lingua galega tan afastadas entre si que se podería dicir que na actualidade xa non ten ningunha utilidade analítica. Así mesmo, asume que non existe un único e cohesiona- 
do discurso reintegracionista senón varios potencialmente tan diverxentes uns verbo dos outros que incluso poderían chegar a excluírse mutuamente. Noutras palabras, semella que as distantes perspectivas que, por tradición, se agruparon baixo a etiqueta de orientación reintegracionista teñen como único elemento común a proposta de achegamento ao padrón ortográfico e gramatical da variedade estándar do portugués pero poden diferir entre si de modo considerable e notorio en canto ao desenvolvemento do proceso de aproximación e en canto ao grao de aveciñamento á variedade estándar do portugués.

Xunto á defensa da necesidade de aproximación á lingua portuguesa, con toda a problemática que esta imprecisa proposta carrexa, a Tese ou Teoría da Reintegración ten outro do seus piares sustentadores na convicción de que galego e portugués non son linguas autónomas unha da outra de acordo a argumentos: a) de natureza lingüístico-científica e b) de índole pragmática.

O primeiro grupo de razoamentos, tal e como aparecen habitualmente na orientación reintegracionista, afirma, en síntese, que galego e portugués non son idiomas independentes un do outro, se temos en conta, ben que a lingua galega e a lingua portuguesa compartiron o período histórico-lingüístico da Idade Media (etapa denominada "galego-portuguesa"), ben que estas dúas linguas comparten un conxunto de atributos básicos de configuración interna ou mesmo en atención a ambas as dúas posibilidades ao mesmo tempo.

O segundo grupo de razoamentos, isto é, aqueles de índole pragmática, defenden basicamente que galego e portugués non son linguas autónomas unha verbo da outra, porque entre os seus falantes é posible, sen necesidade de aprendizaxe previa, a intelixibilidade mutua.

En resumo, a Tese ou Teoría da Reintegración defende que a lingua galega e a lingua portuguesa non son na actualidade (nin o foron no pasado) idiomas autónomos entre si e que, por conseguinte, a lingua galega debería abordar un proceso de converxencia coa variedade estándar do portugués. Non obstante, como acabamos de ver, esta proposta de achegamento á lingua portuguesa queda sen explicitar en canto: $1^{\circ}$ ) ao modo de desenvolvemento do proceso e $2^{\circ}$ ) ao grao de aveciñamento a esta lingua.

Segundo este estado de cousas, na práctica (como de feito así aconteceu), por exemplo as Normas da AS-PG 80 poderían catalogarse como texto da orientación reintegracionista, mais tamén sería factible facer o mesmo co Acordo Ortográfico de Rio (1986).

Abonda con reflexionar un mínimo para advertir que, así formulada, a etiqueta orientación reintegracionista descendería a niveis ínfimos de operatividade metodolóxica visto que os modelos normativos susceptibles de aco- 
modo baixo o epígrafe de corrente reintegracionista poderían chegar mesmo a excluírse mutuamente.

Para restituír certa capacidade analítica ao termo de orientación reintegracionista somos da opinión de que deberiamos retomar, agora en correlato negativo, a aceptación e uso do sistema ortográfico da lingua castelá como fronteira metodolóxica primeira e esencial á hora de elaborar a nómina dos códigos normativos que conforman esta corrente codificatoria. De acordo con esta perspectiva, xa vimos que, avalada nos últimos anos por unha grande maioría de estudosos, o rexeitamento explícito do código ortográfico da lingua castelá sería o criterio central que nos permitiría restrinxir o ámbito da orientación reintegracionista aos seguintes modelos normativos ordenados, en primeiro lugar, por orde cronolóxica, e, en segundo termo, por orde alfabética:

$\left.1^{\circ}\right)$ Directrices para a reintegración lingüistica galego-portuguesa (1979) X.- M. Montero Santalla (en adiante MONT 79).

$2^{\circ}$ ) Orientaçóns para a escrita do noso idioma [1982] da Asociaçóm Sócio-Pedagógica Galega (Normas da AS-PG 82).

$\left.3^{\circ}\right)$ Estudo crítico das Normas ortográficas e morfolóxicas do idioma galego (1983) da Associaçom Galega da Língua (en adiante AGAL 83).

$\left.4^{\circ}\right)$ Método prático de língua galego-portuguesa (1983) de J.-M. Montero Santalha (en adiante MONT 83).

$\left.5^{\circ}\right)$ Prontuário ortográfico da lingua galego-portuguesa (1984) das Irmandades da Fala (desde agora PRONT 84).

6º) Manual de iniciaçom à língua galega (1998) de Maurício Castro Lôpez (en adiante MANUAL 98).

Analizado o núcleo esencial da corrente reintegracionista e antes de entrar de cheo no estudo da corrente codificatoria que ao principio deste traballo denominabamos orientación lusofonófila, gustaríanos comentar unha última particularidade tocante á corrente reintegracionista.

Se reflexionamos con vagar ao redor do que ata este momento viñemos defendendo, semella que non ten demasiada xustificación fragmentar, como por tradición se acostumaba a facer, a orientación reintegracionista en dúas grandes pólas ou subgrupos: a corrente reintegracionista de mínimos (denominada, ás veces, tamén reintegracionismo de mínimos ou norma- 
tiva de concórdia) e a corrente reintegracionista de máximos (tamén chamada, en ocasións, reintegracionismo de máximos). Na nosa proposta, a orientación reintegracionista de mínimos, xunto cos códigos que por costume se lle asocian (cando menos as Normas da AS-PG 79, as Normas da ASPG 80, as Normas da Comisión-Xunta 80, as Normas da CIG e as Normas da APLL), ao aceptaren e usaren o sistema ortográfico do castelán, quedarían fóra da orientación reintegracionista e irían á gabeta da orientación autonomista.

O cadro-resumo desta corrente quedaría conformado, en consecuencia, polos seguintes modelos normativos:

\begin{tabular}{|c|}
\hline ORIENTACIÓN REINTEGRACIONISTA \\
MONT 79 \\
Normas da AS-PG 82 \\
AGAL 83 \\
MONT 83 \\
PRONT 84 \\
MANUAL 98
\end{tabular}

Para finalizar con este primeiro subapartado continuaremos agora a nosa reflexión sobre o debate codificatorio da nosa lingua coa análise da corrente lusofonófila.

Malia que sexa de obrigado recoñecemento que esta corrente ten a súa raíz na orientación reintegracionista, somos da opinión de que o cambio de perspectiva que se produciu a partir do bienio 1985/1986 (do que máis adiante falaremos) é de suficiente entidade como para que poidamos considerar a lusofonía (en ocasións esta foi a súa denominación) como unha corrente codificatoria singularizada verbo do resto.

Se a corrente autonomista e reintegracionista fundamentábanse sobre a Tese da Individualización Sociolingüistica e sobre a Tese da Reintegración respectivamente, a orientación lusofonófila aséntase, segundo os seus propios defensores (Durão 1986), sobre a que eles designan como Tese Unificacionista. Esta Tese, en congruencia co principio de que galego e portugués son a mesma lingua, céntrase, como liña teórico-lingüística, na esixencia dunha mesma e única ortografía para todo o diasistema lingüístico lusófono así como na reivindicación dun padrón ortofónico mínimo común para as variedades lingüísticas que integrarían este espazo lingüístico. Desde esta base, os partidarios da corrente lusofonófila adhírense sen fisuras, aceptan e propugnan como práctica ortográfica para Galicia, nun primeiro momento, o Acordo Ortográfico de Rio (1986) e máis tarde o Acordo Ortográfico de Lisboa (1990), pero, o que aínda é máis relevante, desde a nosa perspectiva, 
rexeitan de modo categórico, e sen ambigüidades, toda posible diverxencia ortográfica coa variedade estándar do portugués.

Basicamente o que pretende a orientación lusofonófila con esta "fuxida cara a adiante", como así lle chaman algúns teóricos do reintegracionismo, é elevar ao máximo nivel as potencialidades de reafirmación da identidade lingüística galega fronte ao idioma castelán utilizando a globalidade de opcións gráficas "símbolo" do ámbito gráfico portugués. De acordo con esta visión dos feitos, a orientación lusofonófila concibe determinados elementos do código ortográfico portugués (p. ex. o til de nasalidade) a modo de "fronteiras símbolo" ou "muros de contención" que deteñan a fagocitación do galego polo castelán.

A corrente lusofonófila constitúe, ao noso entender, unha deriva, en certo modo lóxica e coherente, da corrente reintegracionista se temos presente que, no proceso evolutivo do debate en torno á codificación ortográfica da nosa lingua, foi unha tendencia xeral que cada corrente codificatoria fose cobrando progresivamente cada vez máis consciencia non só dos seus propios principios rectores senón tamén das repercusións e esixencias dos mesmos se procediamos cun mínimo de coherencia interna. Desde este punto de vista a corrente lusofonófila podería entenderse non tanto como unha versión radicalizada do reintegracionismo, como tradicionalmente se viña facendo, senón máis ben como un salto cualitativo na comprensión real das obrigas que traía consigo a posta en práctica do fundamento de que galego e portugués eran unha soa e mesma lingua.

A corrente lusofonófila, polo tanto, é totalmente coherente consigo mesma cando:

$\left.1^{\circ}\right)$ Critica a corrente reintegracionista (fundamentalmente a liña representada pola Associaçóm Galega da Língua) á cal acusa de escasa coherencia interna cando se nega a aceptar en 1989 o til de nasalidade ou a substitución do dígrafo $m b$ por $m$. Segundo a orientación lusofonófila, cando o reintegracionismo rexeita puntos concretos do código ortográfico do portugués como os que acabamos de mencionar sobre o argumento de que se debe buscar unha resposta social mínima que garanta a consolidación e posterior expansión do modelo normativo proposto, acontecen dous feitos que non se poden pasar por alto: a) a corrente reintegracionista estase a redefinir a si mesma no proceso de "integración" na lingua portuguesa, de modo ilexítimo, como estadio e modelo permanente cando, en verdade, o seu único papel lexítimo sería o de etapa provisional e transitoria cara a unha ortografía única para todo o diasistema lusófono e b) se aprofundamos na análise crítica e obxectiva da corrente reintegracionista esta, en última instancia, estaría a validar a Tese ou Teoría da Individualización Sociolingüística ao dar á realidade social, política, económica e cultural que vive hoxe en día a 
lingua galega a pertinencia suficiente como para condicionar o código ortográfico e gramatical do noso idioma,

$2^{\circ}$ ) Cuestiona a denominada ortografía histórico-etimolóxica defendida pola orientación reintegracionista polo que esta ten de atentado contra a unidade ortográfica substanciada na variedade estándar do portugués. Así rexeita, por exemplo, o $m$ final para representar a nasalidade final en vocábulos como nom.

$3^{\circ}$ ) Lamenta as dúas formas de escribir portugués que hai hoxe no mundo (a brasileira e a portuguesa) porque: a) atentan contra a unidade ortográfica do diasistema lusófono e en certo modo, ao nacer e atender a realidades sociolingüísticas diferenciadas, dotan de argumentos mediatos de auto-afirmación á orientación autonomista e b) provocan problemas de tipo práctico á hora de optar por unha ou outra forma de escribir.

$4^{\circ}$ ) Ataca a etiqueta lingua galega porque entende que, de forma directa ou indirecta, permite crear consciencia idiomática.

Unha vez que temos traballado engorde sobre as tres correntes codificatorias que interveñen no debate sobre a codificación ortográfica da nosa lingua, pensamos que, se queremos ter unha visión máis real e profunda do calado e complexidade que acadou a polémica verbo da codificación do idioma galego, non nos deberiamos limitar dun modo estrito ao ámbito exclusivo da planificación da estrutura.

En apoio desta posición metodolóxica, a sociolingüística e a estandardoloxía (p. ex. Joseph 1987, Fodor e Hagège 1983/1990) lémbrannos, sobre todo nos últimos anos, que as diferentes variedades estándar non se poden concibir como entidades completamente fechadas á influencia dos fenómenos de índole socio-cultural e/ou política que as rodean.

Dado que o estudo desta interesante cuestión soborda con moito os límites concretos deste artigo, cremos que, para os nosos intereses, abondaría con lembrar que, hoxe en día, a grande maioría de sociolingüistas poderían estar de acordo coa idea de que non é estraño que o proceso de conformación progresiva dunha nova variedade estándar, así como a súa existencia efectiva, xogue, ou poida xogar, un papel máis ou menos relevante no artellamento gradual dunha novidosa consciencia de identidade nacional autónoma.

Galicia, tal e como entenden non poucos dos que se teñen achegado ao seu debate codificatorio, non sería unha excepción a esta tendencia xeral aos procesos de elaboración das diferentes variedades estándar. Neste sentido, os especialistas no debate codificatorio galego veñen a coincidir, en cantidade crecente, na hipótese de que a polémica sobre a codificación ortográfica da nosa lingua constitúe a codia dunha confrontación moito máis profunda na que se estaría a dirimir en última instancia cál pode ser, ou 
mellor sería dicir cál debería ser, o futuro social, político, económico e cultural da nosa comunidade.

Agora ben, se na "punta de iceberg" da reflexión sobre a identidade futura da comunidade lingüística galega, encontrabámonos con tres correntes codificatorias distanciadas entre si, a bibliografía activa consultada verbo desta problemática dá pé a que, á altura da "base do bloque de xeo", reduzamos estas tres opcións codificatorias a tan só dúas liñas discursivas nas cales a dimensión lingüística, de maior peso específico a nivel superficial, conviviría agora en igualdade coa compoñente ideolóxica.

A liña discursiva ideolóxico-lingüística que subxace á orientación autonomista pon a súa énfase na necesidade dun idioma galego diferenciado fronte á lingua castelá e portuguesa como mecanismo vital para a conformación, ou sería mellor dicir recuperación, dunha consciencia nacional como pobo diferenciado. Desde esta perspectiva semella que a orientación autonomista, como así manifestan os seus teóricos máis destacados (Fernández 1995, Monteagudo 1995, Santamarina 1995), é parte integrante dun discurso nacionalista galego que se opón de forma radical á fagocitación lingüística e cultural promovida desde o mundo lingüístico castelanófono, pero que ademais tamén é abondo prudente co excesivo achegamento ao ámbito lingüístico lusófono. Así entendida, a orientación autonomista contribuiría ao proxecto global do nacionalismo galego de artellamento progresivo e consciente dunha identidade nacional autónoma quen de loitar contra a asimilación lingüística e cultural promovida desde o espacio cultural asociado á lingua castelá.

Pola contra, a liña discursiva ideolóxico-lingüística que durmiña por baixo das orientacións reintegracionista e lusofonófila, de modo máis evidente nesta última, concibe a unidade ortográfica, total ou parcial, co código gráfico da variedade estándar do portugués como un punto de partida previo, necesario e indispensable desde o cal sería factible iniciar a (re-)formulación dunha futura e auténtica identidade nacional galega ao redor de tres grandes opcións políticas: a) Galicia de seu (= nacionalismo galego), b) Galicia con Portugal nun marco político superior (= nacionalismo galego-portugués) e c) Galicia con Portugal, este segundo como nación única (= nacionalismo portugués).

Acéptese ou non esta visión dos feitos (en tanto en canto pode resultar unha perspectiva en exceso anovadora ou arriscada), cremos, así e todo, que non resultaría moi produtivo, desde un punto de vista metodolóxico e analítico, que non deixasemos unha fenda aberta á posibilidade de que semellantes liñas discursivas tivesen unha existencia real na medida en que axudarían a que nos explicasemos: $1^{\circ}$ ) a virulencia que, por veces, alcanzou en Galicia a polémica codificatoria do noso idioma, xa que, ao final, a confrontación non se circunscribiría só ao estrito ámbito ortográfico senón que 
tamén tocaría ao futuro de Galicia como nación e $2^{\circ}$ ) o escaso eco que atinxiu a corrente reintegracionista nos anos máis recentes no conxunto dunha sociedade galega que parece orientarse cada vez máis á demanda de cotas de poder político progresivamente máis elevadas (co horizonte posto nunha Galicia autoxestionada, dentro ou fóra do marco político español) ca á integración no marco político portugués.

\section{AS ETAPAS DO DEBATE NORMATIVO}

O profesor Johannes Kabatek (1994) diferenciaba a mediados dos anos 90 do século pasado catro grandes etapas ou fases no debate normativo da nosa lingua: a) anterior a 1936, b) de 1936 a 1966, c) de 1966 a 1982 e d) de 1982 ata a actualidade. Da periodización feita por este estudoso sobre a progresión do debate normativo interésanos destacar a súa apreciación, na cal coincide con outros moitos investigadores, de que aproximadamente ata 1977 a polémica sobre esta cuestión moveuse, polo xeral, dentro dun clima xeral de diálogo e tolerancia.

En 1977 saíron á rúa as Bases prá unificación das normas lingüísticas do galego, feito que convertirá a este ano nunha data clave na progresión do debate normativo. Segundo o profesor Henrique Monteagudo Romero (1993) este texto significará un caso insólito e puntual de consenso normativo na historia da controversia codificatoria da nosa lingua. E isto foi así porque na súa redacción e elaboración tomaron parte activa mestres, filólogos e escritores de todo signo e condición. Nos seminarios previos ás Bases prá unificación das normas lingüisticas do galego celebrados desde decembro de 1976 a xuño de 1977 participaron todos aqueles que no momento tiñan algo que dicir sobre a codificación ortográfica e gramatical do noso idioma, mesmo, como se pode comprobar na revista Teima (Rivas 1977: 41-43) significados reintegracionistas como X.- M. Montero Santalla e J. L. Rodríguez. O talante conciliador que aínda impregnaba o debate sobre a codificación da nosa lingua en datas próximas a 1977, faise explícito cando X.- M. Montero Santalla lle confesa a X. Ferro Ruibal (1984: 278) que el "defendía a súa opción lusista, pero que, se perdía, el someteríase, porque era máis importante a normalización cá normativización".

Porén, en poucos anos, en concreto no período que abrangue de 1977 a 1982, ou se así se prefire no bienio 1979/1980 visto que o que acontece con posterioridade semella ter a súa raíz nestes dous anos, teñen lugar unha serie de sucesos que, ao noso entender, marcan un primeiro punto de inflexión na progresión histórica do debate normativo sobre o noso idioma. Este salto cualitativo na polémica ortográfica arrinca no instante en que a corren- 
te reintegracionista comeza a cobrar plena consciencia das obrigas que carrexaba consigo o principio de que galego e portugués non son, entre si, linguas autónomas. Noutras palabras, a progresión histórica do debate codificatorio do idioma galego entrou nunha nova dimensión cando, ao callar, cristalizar e primar sobre outras consideracións os principios rectores da propia orientación reintegracionista, isto, se se procedía cun mínimo de coherencia interna, impedía: $1^{\circ}$ ) continuar coa práctica de anos anteriores de achegar solucións puntuais máis ou menos reintegracionistas a modelos normativos en esencia autonomistas e $2^{\circ}$ ) aceptar a posibilidade dun acordo efectivo coa orientación autonomista.

Deste modo, a corrente reintegracionista escorou, guiada sempre por criterios de coherencia interna, desde unha previa vontade de concordia que permitira os acordos das Bases prá unificación das normas lingüisticas do galego de 1977 cara a un talante posterior de confrontación aberta coa orientación autonomista. Os feitos denotadores desta viraxe, que en parte xa comentamos máis arriba, foron, segundo o noso parecer, os seguintes:

$\left.1^{\circ}\right)$ En 1979 destacados lingüistas como R. Carballo Calero e X.- M. Montero Santalla decláranse, a través dos textos que publican, abertamente reintegracionistas. Carballo Calero publica ese ano a $7^{a}$ edición da Gramática elemental del gallego común, na que revisa os postulados das seis anteriores desde un punto de vista reintegracionista, e X.-M. Montero Santalla dá ao prelo as Directrices para a reintegración lingüistica galego-portuguesa onde nega categoricamente a posibilidade de acordo entre a orientación reintegracionista e autonomista (Montero 1979: 3-4).

$2^{\circ}$ ) O 17 de maio de 1980 créase a Associaçóm Galega da Língua que se legaliza o 20 de maio dese mesmo ano. A AGAL, que terá entre os seus fundadores a personalidades como R. Carballo Calero, J. L. Rodríguez e X.-M. Montero Santalla, establecerá como obxectivo fundamental, de acordo aos seus estatutos, conseguir unha fundamental reintegración do galego (principalmente das súas manifestacións escritas) na área cultural e lingüística galego-portuguesa.

$3^{\circ}$ ) En 1980 publícanse as Normas da Comisión-Xunta 80. Estas normas constitúen na práctica unha conxunción entre dous modelos normativos aglutinados en torno a principios radicalmente opostos entre si, o que podería constituír outra proba evidente de que ao redor de 1979/1980 comezaban a callar, cristalizar e primar sobre outras consideracións os principios rectores de cada corrente normativa.

4º) Desde 1979 a 1982 a Asociación Sócio-Pedagóxica Galega experimenta unha evolución interna marcada por unha progresiva bifurcación de correntes de opinión entre un sector maioritario máis achegado ás posicións lingüísticas da orientación autonomista, aínda que, na opinión do investi- 
gador Antón Santamarina (1995), con diverxencias puntuais coas NOMIG 82 de natureza esencialmente política máis ca lingüística, e un sector minoritario cada vez máis próximo á orientación reintegracionista.

Segundo J. L. Fontenla Rodrigues (1986: 57) o día 23 de xaneiro de 1982 celébrase unha primeira reunión a instancias da AS-PG para elaborar un código normativo máis acorde coa liña de pensamento lingüístico defendido pola corrente reintegracionista. A esta primeira reunión acoden entre outros: R. López Suevos, J. L. Fontenla, F. Rodríguez, P. García Negro, X.- M. Montero Santalla e S. Esteban Radío. Nesta primeira reunión formúlase a posibilidade de introducir na futura normativa o acento circunflexo, o ç e o $s$ duplo, proposta que J. L. Fontenla (1986), sen dar máis detalles, di que unha parte dos alí reunidos rexeita. Nunha segunda sesión celebrada o 8 de maio de 1982, na que Fontenla recoñece que non están todos os que participaron na primeira reunión, acéptase como posibilidade a pé de páxina o acento circunflexo, o $s$ duplo e os plurais en -õis e -ôes.

En consecuencia, as Orientaçóns para a escrita do noso idioma, que figuran con data de 1980, aínda que en realidade son de 1982, defenden escollas ortográficas que non foron aceptadas pola totalidade de membros que daquela conformaban a AS-PG. O mesmo acontece cunha serie de folletos posteriores que levan por título Para ler textos escritos en galego (1982), Observaçóns sobre as normas ortográficas e morfolóxicas do Instituto da Lingua Galega-Real Academia Galega (1982) e Explicaçóns sobre algúns pontos das Orientaçóns para a escrita do noso idioma (s.d.).

Se o período que vai de 1977 a 1982 marcaba un punto de inflexión na progresión histórica do debate codificatorio da nosa lingua, a partir de 1985 asistimos ao inicio dun novo salto cualitativo na evolución do debate ortográfico do idioma galego. Neste espacio cronolóxico entrará en escena unha nova corrente codificatoria, a orientación lusofonófila, que nace, de acordo ao noso punto de vista, cando a inminencia para a lingua portuguesa do Acordo Ortográfico de Rio (1986) aboca, por vez primeira, aos colectivos galegos que defenden que o galego e o portugués son unha mesma lingua a un exercicio inescusable de coherencia interna verbo dos seus propios postulados. Isto obrigaralles, na práctica, a: $1^{\circ}$ ) participar neste e en posteriores acordos ortográficos da lingua portuguesa e $2^{\circ}$ ) levar a efecto en Galicia o Acordo Ortográfico de Rio (1986), primeiro, e, máis tarde, o Acordo Ortográfico de Lisboa (1990).

A corrente lusofonófila aparece como orientación individualizada para a codificación ortográfica do idioma galego en 1985 cando no IV Encontro Internacional da Lingua Galaico-portuguesa, celebrado en Pontevedra nos días 6 e 7 de decembro dese mesmo ano, tómase a decisión de crear unha Comissão para a integração da Lingua da Galiza no Acordo Ortográfico 
Luso-Brasileiro (en adiante COM 85). Forman parte da COM 85, entre outros, os seguintes colectivos: Irmandades da Fala da Galiza e Portugal, Associação de Amizade Galiza-Portugal, Associação Sócio-Pedagógica Galaico-Portuguesa e Associação Pedagógica Jornadas do Ensino de Galiza e Portugal. A COM 85 decide intervir no Acordo Ortográfico de Rio (1986) por medio dunha delegación de "observadores de Galicia" integrada por tres membros: J. L. Fontenla, A. Figueroa e I. A. Estravis, facultada para tomar decisións e colaborar en representación da COM 85.

Malia que a delegación de "observadores de Galicia" non conseguiu introducir ningunha das súas propostas, manifestaron de modo público a súa adhesión ao Acordo Ortográfico de Rio (en adiante AOR 86) de modo que as organizacións non gobernamentais xa mencionadas, xunto coa asociación Escritores em Língua Galego-Portuguesa, foron as únicas (xunto con outras no Xapón) que o levaron á práctica dado que este acordo, que debería ter entrado en vigor o 1 de xaneiro de 1988, fracasou nos países de fala portuguesa debido á oposición xurdida en Portugal.

Ante o fracaso do AOR 86 e diante do novo acordo que se aveciña para a lingua portuguesa en 1988 créase unha segunda Comissão para a integração da Lingua da Galiza no Acordo de Ortografia Unificada (en adiante COM 88). A COM 88 acode ao Encontro da Unificação Ortográfica, celebrado na Academia de Ciências de Lisboa do 8 ao 12 de decembro de 1990, representada por unha nova delegación de "observadores de Galicia" integrada agora por J. L. Fontenla e A. Gil Hernández. A pesar de que esta delegación só logrou introducir no Acordo Ortográfico de Lisboa (1990) as palabras esdrúxulas brétema e lóstrego (coas grafías brêtema e lôstrego, pasan a ser galeguismos no portugués), apoia publicamente o Acordo Ortográfico de Lisboa (en adiante AOL 90).

Para finalizar esta panorámica, presentamos a continuación o cadro-resumo que recolle as tres correntes codificatorias no debate ortográfico e gramatical da nosa lingua, así como os códigos normativos que integran cada unha destas orientacións:

\begin{tabular}{|lcc|}
\hline ORIENTACIÓN AUTONOMISTA & ORIENTACIÓN REINTEGRACIONISTA & ORIENTACIÓN LUSOFONÓFILA \\
Normas da AS-PG 79 & MONT 79 & AOR 86 (COM 85) \\
Normas da AS-PG 80 & Normas da AS-PG 82 & AOL 90 (COM 88) \\
Normas da Comisión-Xunta 80 & AGAL 83 & \\
Normas da Subcomisión-Xunta 80 & MONT 83 & \\
NOMIG 82 & PRONT 84 & \\
Normas da CIG & MANUAL 98 & \\
Normas da APLL & & \\
\hline
\end{tabular}




\section{REFERENCIAS BIBLIOGRÁFICAS}

Durão, C. (1986): “A ortografia comum galego-portuguesa. Para um acordo ortográfico galego-luso-brasileiro-africano da língua portuguesa. Uma proposta galega”, Temas de O Ensino II, 6/10, 79-88.

Fernández Rei, F. (1995): “A 'questione della lingua' galega”, en H. Monteagudo (ed.): Estudios de sociolingüistica galega. Sobre a norma do galego culto. Vigo: Galaxia, 177-195.

Fernández Salgado, B. / H. Monteagudo (1995): "Do galego literario ó galego común. O proceso de estandardización na época contemporánea”, en H. Monteagudo (ed.): Estudios de sociolingüística galega. Sobre a norma do galego culto. Vigo: Galaxia, 99-176.

Ferro Ruibal, X. (1984): "O acordo ortográfico morfolóxico de 1982. Entre a utopía foneticista e as heterografías lusistas", en I Encontros Labaca. Ponencias. Sada: Ed. do Castro, 176-307.

Fodor, I. / C. Hagège (eds.) (1983-1990): Language Reform / La réforme des langues / Sprachreform. 5 vols. Hamburg : Helmut Buske Verlag.

Fontenla, J. L. (1986): "Breve história do conflito linguístico na Galiza: a normativa do galego desde a II república até hoje", Temas de O Ensino II, 6/10, 51-68.

Herrero Valeiro, M. J. (1991-1994): "Ciência e ideologia na investigação sociolinguística na Galiza”, Temas de O Ensino VII/IX, 27/38, 195-205.

Herrero Valeiro, M. J. (1993): "Guerre des graphies et conflict glottopolitique: lignes de discours dans la sociolinguistique galicienne", Plurilinguismes 6, 181-209.

Joseph, J. E. (1987): Eloquence and power. The rise of language standards and standard languages. London: Frances Pinter.

Kabatek, J. (1992): "Der Normenstreit in Galicien: Versuch einer Erklärung", Lusorama 18, 65-83.

Kabatek, J. (1994): "Galego escrito e galego común na segunda metade do século XIX”, Grial 122, 157-179.

Lapa, M. Rodrigues (1973): "A recuperação literária do galego", Grial 41, 278-281.

Monteagudo, H. (1993): “Aspects of corpus planning in Galician”, Plurilinguismes 6, 121-153.

Monteagudo, H. (1995): "Sobre a polémica da normativa do galego", en H. Monteagudo (ed.): Estudios de sociolingüistica galega. Sobre a norma do galego culto. Vigo: Galaxia, 197-229.

Montes Giraldo, J. J. (1986): "Lengua-dialecto una vez más. La persistencia y actualidad de un viejo problema", Thesaurus 41, 1-2-3, 23-41. 
Muljačić, Ž. (1990): "L'italien est-il une langue polynomique?", en J. Chiorboli (ed.): Corti 90. Actes du Colloque international des langues polynomiques. Université de Corse, 17-22 septembre 1990. Publications Universitaires de Linguistique et d'Anthropologie (PULA), 3-4, Corti (1991), 338-343.

Muljačić, Ž. (1991a): "L’approccio relativistico", Rivista italiana de dialettologia. Lingue dialetti società, 15, 183-190.

Muljačić, Ž. (1991b): "Per un approccio relativistico al rapporto: lingua nazionale-dialetti", en Fra dialetto e lingua nazionale: realtà e prospettive. XVIII Convegno di Studi Dialettali Italiani (Lugano 11-15 ottobre 1988). Lugano/Padova: Unipress, 247-259.

Muljačić, Ž. (1991c): "Sullo status linguistico dell'istrioto mediavale", Linguistica XXXI (Paulo Tekavcic sexagenario in honorem oblata, I), 155-170.

Muljačić, Ž. (1995): "A estandardización do galego e outros casos europeos", en H. Monteagudo (ed.): Estudios de sociolingüistica galega. Sobre a norma do galego culto. Vigo: Galaxia, 19-51.

Muljačić, Ž. (1999): "Estandardización de linguas románicas ‘baixo presión': unha proposta tipolóxica”, en F. Fernández Rei / A. Santamarina Fernández (eds.): Estudios de sociolingüística románica. Lingua e variedades minorizadas. Santiago: Universidade, 11-26.

Rivas, M. (1977): "Poñerlle pés á lingua escrita", Teima 22, 41-43.

Sánchez Vidal, P. (2000): Contribución ó estudio do proceso de codificación ortográfica e gramatical do galego: orientacións, conflicto e fases do debate normativo. Memoria de licenciatura. Universidade de Santiago.

Santamarina, A. (1995): "Norma e estándar", en H. Monteagudo (ed.): Estudios de sociolingüistica galega. Sobre a norma do galego culto. Vigo: Galaxia, 53-98.

Taschenberger, S. (1990): "Zur Rolle des orthographisch-morphologischen Abkommens (AOM-82), in der linguistischen Auseinandersetzung zwischen Realismus und Reintegrationismus in Galicien”, Beiträge zur Romanischen Philologie 29, 135-142. 